\title{
Direct and Indirect Effects of Invasive vs. Native Ant-Hemipteran Mutualism: A Meta-Analysis That Supports the Mutualism Intensity Hypothesis
}

\author{
Bo Wang ${ }^{1,2, *}$, Min Lu ${ }^{3}$, Yan-Qiong Peng ${ }^{1,2} \mathbb{D}$ and Simon T. Segar ${ }^{4} \mathbb{C}$ \\ 1 CAS Key Laboratory of Tropical Forest Ecology, Xishuangbanna Tropical Botanical Garden, \\ Chinese Academy of Sciences, Menglun 666303, China; pengyq@xtbg.ac.cn \\ 2 Center for Plant Ecology, Core Botanical Gardens, Chinese Academy of Sciences, Mengla 666303, China \\ 3 State Key Laboratory of Biocatalysis and Enzyme Engineering, School of Life Sciences, Hubei University, \\ Wuhan 430062, China; lumin@hubu.edu.cn \\ 4 Agriculture and Environment Department, Harper Adams University, Newport, Shropshire TF108NB, UK; \\ ssegar@harper-adams.ac.uk \\ * Correspondence: wangbo@xtbg.ac.cn
}

Citation: Wang, B.; Lu, M.; Peng, Y.-Q.; Segar, S.T. Direct and Indirect Effects of Invasive vs. Native Ant-Hemipteran Mutualism: A Meta-Analysis That Supports the Mutualism Intensity Hypothesis. Agronomy 2021, 11, 2323. https:// doi.org/10.3390/agronomy11112323

Academic Editor: Tran Dang Xuan

Received: 26 September 2021

Accepted: 14 November 2021

Published: 17 November 2021

Publisher's Note: MDPI stays neutral with regard to jurisdictional claims in published maps and institutional affiliations.

Copyright: () 2021 by the authors. Licensee MDPI, Basel, Switzerland. This article is an open access article distributed under the terms and conditions of the Creative Commons Attribution (CC BY) license (https:// creativecommons.org/licenses/by/ $4.0 /)$.

\begin{abstract}
Mutualism can facilitate the colonization, establishment, and spread of invasive species. By modifying interactions with third parties, mutualisms can have cascading community-wide effects. Both native and invasive ants are capable of forming mutualisms with hemipteran insects, preying on non-hemipteran herbivores and indirectly affecting primary production. Comparative research on the effects of both native and invasive ant exclusions on multitrophic interactions is therefore crucial for understanding the invasive potential of ants, along with any ecological consequences that invasions may have. We performed a quantitative review of the multitrophic effects of invasive and native ants on insect-plant food webs. Herbivorous insects are the most common food source for both invasive (comprising $56 \%$ of prey species caught) and native ants (55\% of the prey species caught), followed by predators ( $31 \%$ for invasive ants, $45 \%$ for native ants). Excluding both invasive and native ants significantly reduced hemipteran abundance, and excluding invasive ants had a greater negative impact on hemipteran abundance than native ants. Native ant predation significantly reduced herbivore abundance, but excluding invasive ants had no effect. Cascading effects of native ants on plant fitness were significantly positive, but there was no significant impact of invasive ants. These findings suggest a weak relationship between the presence of invasive ants and non-hemipteran herbivore abundance. We suggest that the hemipteran-ant mutualism could represent a 'symbiotic invasion'. The ecological dominance of invasive ants is often facilitated by hemipteran insects. This association requires invasive ant control strategies to expand beyond ants to consider mutualists.
\end{abstract}

Keywords: invasive ant; ant-hemipteran mutualism; trophic cascade; meta-analysis

\section{Introduction}

Biological invasion is not only a threat to biodiversity but also leads to enormous economic and ecological costs [1,2]. During the process of invasion, exotic species encounter several biotic and abiotic barriers to colonization, survival, regeneration, and dispersal [3]. However, both native species and exotic species may promote bio-invasion by establishing new mutualistic interactions with invaders [4-8]. Different types of mutualistic interactions (e.g., mutualisms between plant microbe, plant pollinator, plant seed disperser, and insect microbe) have been reported for both invasive plants $[9,10]$ and invasive animals $[4,5,11]$. Mutualists may promote the colonization and establishment of alien species through pollination, seed dispersal, and nutrient supply, having cascading effects on wider modules of the community [4].

Ants (Hymenoptera: Formicidae) are among the most diverse and abundant insects on this planet; their elaborate social behavior, territoriality, and polyphagous feeding behavior 
make them one of the most widespread and ecologically important invasive taxa [12-15]. Approximately 235 ant species are classified as exotic species, with 115 of these having been successfully established outside of their native range, but this number is likely an underestimate [16].

Mutualisms between ants and insects in the order Hemiptera (e.g., aphids, whiteflies, scale insects, treehoppers, leafhoppers, and mealy bugs) are called trophobiosis [15,17-19]. Ants protect hemipterans from predation (e.g., by ladybirds, lacewings, and spiders) or parasitism by wasps [6,8], while hemipterans provide honeydew to ants as a source of carbohydrates (Figure 1a) $[7,20,21]$. In addition to enhancing the fitness of their hemipteran partners, ant predation or harassment of other herbivorous insects can impact plant fitness [22-25]. The exact outcome of these interactions is generally context dependent $[19,26]$. Both invasive ants and native ants can form trophobiosis with hemipteran insects [27-29]. Although some native ants negatively impact host plant seed production [30-32], native ants generally coexist with arthropods in the community, and they can reduce host plant damage via predation of herbivores, thus promoting plant reproduction [33,34]. In contrast, invasive ants generally prey on all guilds of arthropods; they have been reported to be detrimental to local populations of invertebrate [35-37], while both positive [38] and negative [39] effects on plants have been found.

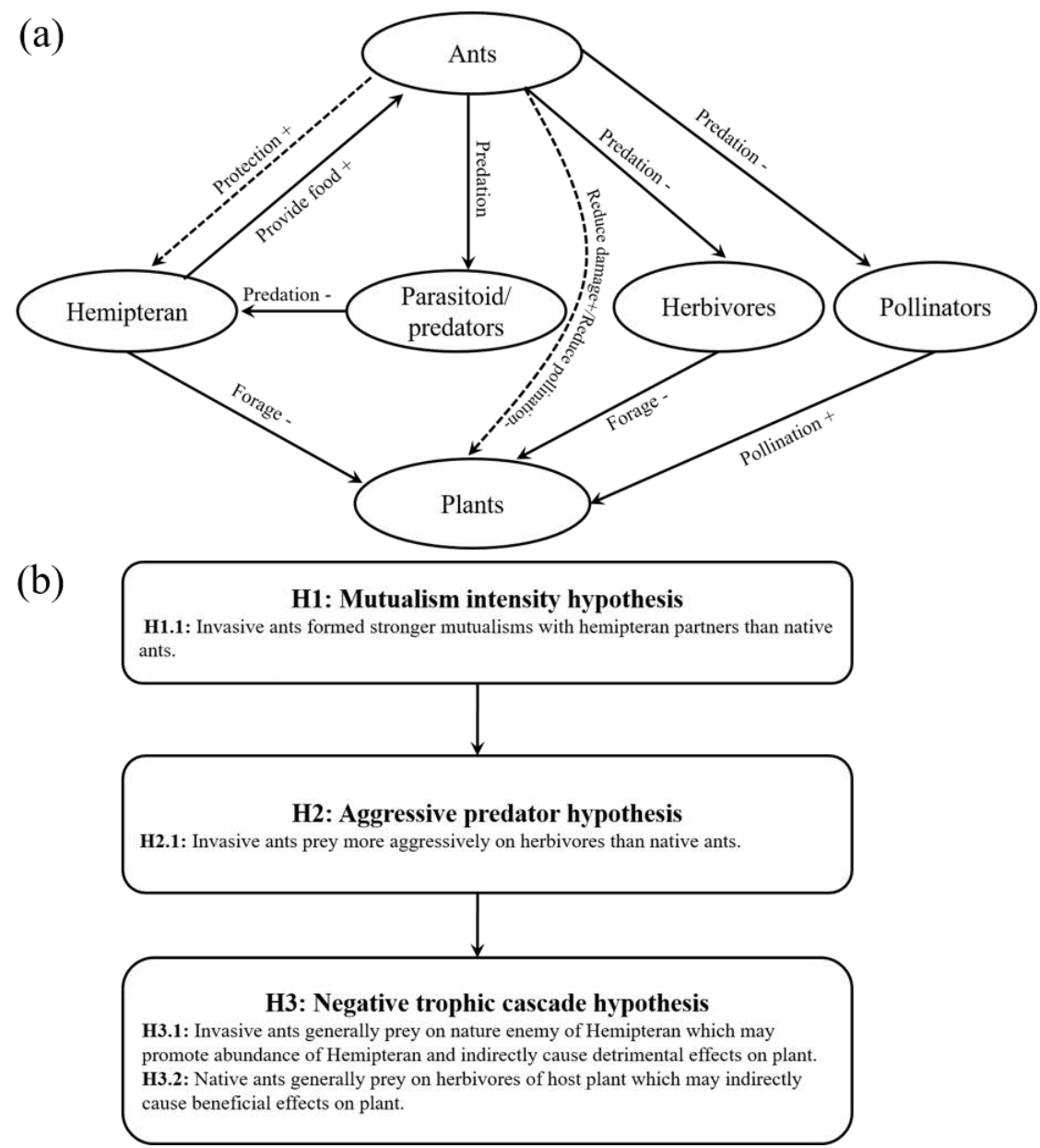

Figure 1. (a) Ants protect Hemiptera from preying/parasitic predators (e.g., ladybird, lacewing flies, spiders) or parasitic wasps, and hemipterans provide honeydew to ants as food hydrocarbon source. Ant predation or harassment on herbivores will have cascading effects on plant fitness. (b) Proposed hypotheses on cascading effects of both native and invasive ants on the local arthropod community and plant fitness. 
Cascading effects of both native and invasive ants on local arthropod communities and plant fitness are thought to result from one general mechanism (Figure 1a), but at least three consecutive pathways have been put forward to explain this phenomenon (Figure 1b). First, interactions between invasive ants and Hemiptera may be stronger than interactions between hemipterans and native ants ( $\mathrm{H} 1$ : the "mutualism intensity" hypothesis). In this scenario, both native and introduced ant species perform identical roles within communities, but the magnitude of any ecological effect is more pronounced in invasive ants due to a greater intensity of mutualistic interactions. If true, excluding invasive ants would lead to a stronger decline in hemipteran abundance relative to native ant exclusion. Further, any differences in broader ecological impact would be primarily explained by mutualism intensity. Alternatively, the observed differences in the broader ecological effects of native versus introduced ant species might result solely from differences in the magnitude of ant aggression and predation (H2: the "aggressive predator" hypothesis). In this framework, native and introduced ant species consume similar groups of taxa, but invasive ants consume prey at a higher rate than native ant species and/or display more intense aggression towards prey taxa. Finally, indirect effects on local plant performance or fitness might differ because native and introduced ants fulfill distinct roles within ecosystems (H3: the "negative trophic cascade" hypothesis). If invasive ants prey equally on herbivores, host plant pollinators, and natural enemies of hemipterans (e.g., parasitoids, spiders, and ladybirds), and if native ants generally prey on herbivores of the host plant (e.g., caterpillars, weevils, seed predators), then indirect effects of ants on plants might be more positive when native ants are present relative to their invasive counterparts.

In addition to the relative magnitude of species interactions outlined by Styrsky and Eubanks [26], other factors will affect the ant-hemipteran interaction and its cascading effects on arthropods and plant fitness. First, climatic zone (temperate, subtropical, or tropical) is a potentially important factor; this is because species interactions are assumed to be stronger in the tropical zone than in temperate regions [40]. Second, the taxonomic group of Hemiptera considered (e.g., aphids, scales, and treehoppers) may influence ant and herbivore behavior and abundance, and consequently plant fitness. Third, all the interactions occur on host plants, making plant growth form another key factor that may dramatically modify the ant-hemipteran interaction and its general ecological consequences. To date, most research has focused on only one or two levels of interaction between ants, other arthropods, and plants, and few studies have focused on the potential effects of ant-hemipteran trophic interactions as a whole.

We conducted three related meta-analyses based on data from invasive or native ant exclusions and resultant measures of hemipteran abundance, herbivore abundance, and plant fitness (measures on plant performance and reproduction). Exclusion experiments were commonly conducted and compared with a control (ant presence) to test the direct and indirect ecological consequences of ant exclusions. Specifically, this paper addressed the following two questions: (1) How do native and alien ants influence hemipteran abundance, herbivore abundance, and plant fitness? (2) Are any of these effects modified according to by climatic zone hemipteran taxon, or plant type?

\section{Materials and Methods}

\subsection{Data Search}

We performed a systematic search for experimental studies that evaluated the effect of ant and hemipteran interactions on arthropod communities and plant fitness on 8 May 2018. Searches were carried out in the electronic databases Science Direct, ISI Web of Science, and Wiley online library using the following combinations in keywords and abstract and title (ant* AND (hemiptera* OR homoptera* OR honeydew) AND (exclu* OR remov*) AND (plant* OR "plant reproduction" OR seed*). The initial literature search resulted in 1277 published articles. We then assessed the relevance of the articles based on titles and abstracts to determine their potential for meeting our selection criteria and their validity for subsequent inclusion in the meta-analysis. We also included articles from the reference 
list of retrieved articles [26,41,42]. During the process of literature selection, we recorded the number of articles identified and the number of studies included/excluded based on our inclusion criteria following the Preferred Reporting Items for Systematic Reviews and Meta-analysis [43]. Finally, 54 references that included exclusion ant experiments on either hemipteran abundance, herbivore abundance, or plant fitness were included in the analysis. Citations for all the 54 references are listed in the Supplementary Materials S1 and detailed information for each experiment can be found in Supplementary Materials S2.

\subsection{Criteria for Data Selection}

Our selection criteria required that studies should (1) be peer-reviewed, (2) include data on ant-hemipteran interactions, and (3) quantitatively compare the abundance of hemipterans, non-hemipteran herbivores, or any measurements related to plant fitness (e.g., plant growth, height, seed production, leaf area, bud number) based on exclusion experiments in both field and lab conditions. The term "abundance" denotes the total number of individual hemipterans or herbivores collected per unit of plant or plant part. Because most studies only recorded one or some of the measurements, the abundance of hemipterans and/or herbivores and/or plant fitness may come from different studies. If a reference reported results for more than one site, we regarded each site as an independent study. The effect on each species was regarded as an independent observation when a study yielded data on multiple herbivore taxa. For repeated measures, we only included the final observation in the analyses.

\subsection{Data Extraction and Effect Size Metrics}

For each study, we classified the prey of ants into herbivores, predators, and pollinators. We also recorded mean, standard deviation (SD), and sample size for abundance of hemipteran, herbivore, and plant fitness. For articles that did not report means and variation in tables, these statistics were extracted by digitizing graphs using the image processing software Image [44]. For studies that provided standard error (SE), we transformed SE to SD. We then calculated effect size as Hedges' g, which was chosen because it corrects for differences in sampling effort among studies and adjusts for small sample size [45]. Negative values of Hedges' g denote a lower value in an ant exclusion experiment in comparison to the control.

\subsection{Categories}

Because different species of ant, hemipteran insect, prey, and plant were involved in the meta-analysis, a high heterogeneity of effect size variance was expected in the analysis. Climatic zone may affect ants, hemipteran, prey behavior, and plant development, and as such, we included the climatic zone (with three levels, temperate, subtropical, and tropical) in our analysis to explain the heterogeneity in effect size. We also divided the data by hemipteran superfamily: aphids (superfamily Aphidoidea), treehoppers (superfamily Membracoidea), and scale insects (superfamily Coccoidea). Because ant-hemipteran interactions occur on the host plant, we included the plant growth form (with three levels, tree, shrub, and herb) as a variable that may affect invasive/native ant effects on arthropod and plant fitness.

\subsection{Data Analysis}

We extracted data for hemipteran abundance, herbivore abundance, and plant fitness as separate variables, and three meta-analyses on each data type were performed separately. The invasive ants included in the analysis are Anoplolepis gracilipes, Linepithema humile, Myrmica rubra, Solenopsis invicta, Tapinoma melanocephalum, and Technomyrmex albipes. Over 20 native ant species are included in the analysis. Random effects models for meta-analysis were fitted for the analysis, with Hedges's g as the response variable, invasion (with two levels, invasive ant, native ant), hemipteran superfamily (with three levels, aphid, 
treehopper, scale), plant growth form (with three levels, tree, shrub, herb), and climate zone (with three levels, tropical, subtropical, temperate) as the explanatory variables.

Before each analysis, outliers were visualized using box plots and further tested using Grubbs' test [46] in R 3.5.1 [47]. Sensitivity analyses were conducted to assess how our initial analysis was sensitive to outliers [48]. For the meta-analysis, we used random effects models to compare the difference between invasive and native ants. We selected QM (Q-statistic for model fit) as the statistic because it is a standardized measure unaffected by the metric of the effect size index. We estimated the $95 \%$ CI for $g$ of invasive and native ants [49]. We also estimated the influence of publication bias using a funnel plot and Egger's regression test for funnel plot asymmetry [50]. The trim-and-fill method was used to adjust for funnel plot asymmetry, and a random effect model was fitted to the new data. All data analyses were performed using the "metafor" R package [51].

\section{Results}

\subsection{Prey Categories across Native and Invasive Ants}

Herbivores are the most common food source for both invasive (56\% of the prey species caught) and native ants (55\% of the prey species caught), followed by predators (31\% for invasive ants, $45 \%$ for native ants). Pollinators are not common food items for ants, maybe because pollinators are generally flying insects and are difficult for ants to catch. Finally, invasive ants do not capture more pollinators compared to native ants.

\subsection{Effects of Invasive/Native Ant Exclusion on Hemipteran Abundance}

We removed five observations where the mean number of hemipteran insects was zero. Four outliers were detected, with extremely positive effect sizes 0.79 ( ) and extremely negative values $-3.88,-4.06,-4.60()$. Outliers did not influence the significance of ant exclusion on hemipteran abundance for either native or invasive ants. However, when the outliers were included, the difference of effect size between invasive and native ants was not significant $(\mathrm{z}=0.75, p=0.45)$.

We combined 42 studies reporting the effects of ant exclusion on hemipteran abundance in our meta-analysis, once outliers had been excluded. Egger's regression test for funnel plot asymmetry showed significant asymmetry of these data $(\mathrm{t}=-4.89$, d.f. $=40$, $p<0.001$; Supplementary Materials S3, Figure S1). A trim-and-fill method added an additional 16 artificial observations to the original data. With this data, the effects of exclusion ants on hemipteran abundance were significantly negative $(z=-6.42, p<0.001)$.

The global effects of ant exclusion on hemipteran abundance were significantly negative for both invasive and native ant species (Figure 2a; Supplementary Materials S4, Table S1). The comparison between invasive and native subgroups showed that invasive ants had significantly more detrimental effects on hemipteran abundance than native ants (Figure 3a, $\mathrm{z}=2.69, p<0.01$ ).

Effect sizes were then categorized by climatic zone. In the tropical zone, exclusion of both native and invasive ants had a significant negative effect on hemipteran abundance (Supplementary Materials S4, Table S1). A between-group (invasive and native ants) comparison showed that exclusion of invasive ants had significantly greater detrimental effects on hemipteran abundance than native ants $(\mathrm{QM}=8.60$, d.f. $=1, p<0.01$, Figure $3 b)$ in the tropical zone.

We then categorized data by hemipteran superfamily. For each superfamily of hemipteran, effects of ant exclusion (invasive and native) had significant effects on hemipteran abundance (Supplementary Materials S4, Table S1). For ant-aphid interactions, no significant betweengroup difference was found $(\mathrm{QM}=2.48$, d.f. $=1, p=0.12$, Figure $3 \mathrm{c})$. For ant-scale interactions, no significant difference was found between invasive and native ants $(\mathrm{QM}=0.54$, d.f. $=1, p=0.46$, Figure 3c). 
(a) Hemipteran abundance

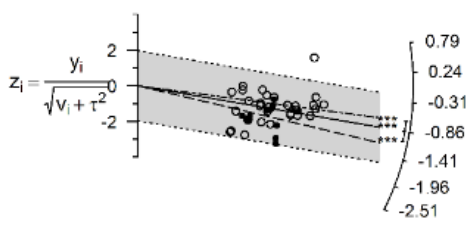

$\begin{array}{llllll}0.0 & 0.5 & 1.0 & 1.5 & 2.0 & 2.5\end{array}$

$x_{i}=1 / \sqrt{v_{i}+\tau^{2}}$

(c) Predator abundance

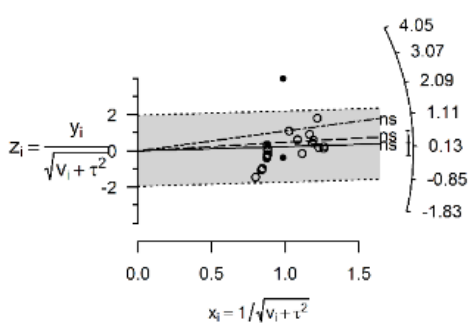

(b) Herbivore abundance

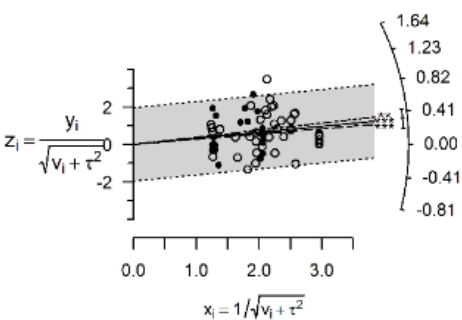

(d) Plant fitness

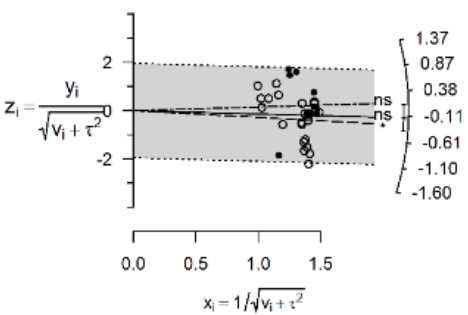

Figure 2. A radial plot of Hedges' g obtained from invasive vs. native ant exclusion on (a) hemipteran abundance of 43 studies, (b) herbivores abundance of 62 studies, (c) predator/parasitoids abundance of 50 studies, and (d) plant fitness of 34 studies, all for random-effects model. These are scatter plots of standardized estimates $z_{i}$ against precisions $x_{i}$, where $y_{i}$ and $v_{i}$ are Hedges' $g$ and standard deviation for each study, and $\tau^{2}$ represents the variance of global standardized mean difference (SMD). Circles represent Hedges' g of native ants, and dots are the invasive ants. The straight line projected from $(0,0)$ onto the arc indicates the value of the global SMD, areas between the dotted line give the $95 \%$ confidence interval. The dashed line projects the SMD of native ants, the dash-dot line the SMD of invasive ants. ${ }^{*} p<0.05,{ }^{* *} p<0.01,{ }^{* * *} p<0.001$, "ns" not significant. The null hypotheses here are that the effects size equal zero.

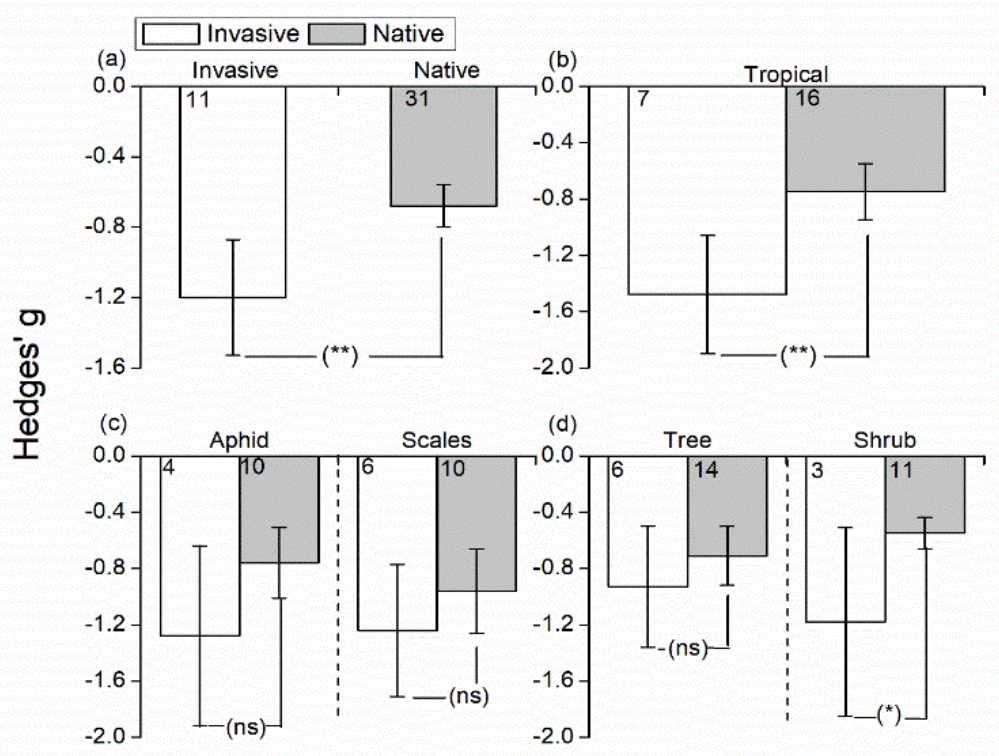

Figure 3. Mean effect size (Hedges' g) and 95\% confidence interval of the effect of exclusion invasive or native ants on Hemiptera abundance (a) under different climatic zones (b), Hemiptera type (c), and plant growth form (d). Sample sizes for each category are shown in box. ${ }^{*} p<0.05,{ }^{* *} p<0.01$, "ns" not significant. 
Finally, we categorized data by plant growth form. For each plant growth form, effects of exclusion of both invasive and native ants had significant effects on hemipteran abundance (Supplementary Materials S4, Table S1). Within the trees, the between-group difference was not significant $(\mathrm{QM}=0.93$, d.f. $=1, p=0.33)$, and within the shrubs, a significant between-group difference was observed ( $Q M=6.02$, d.f. $=1, p<0.05$, Figure 3d).

\subsection{Effects of Invasive/Native Ant Exclusion on Herbivore Abundance}

We removed three observations where the mean number of herbivores was zero in the controls. Six outliers were detected and removing outliers did not influence the global effects $(z=5.75, p<0.0001)$ of ant exclusion on herbivore abundance and the effects of native $(\mathrm{z}=4.44, p<0.001)$ and invasive ants $(\mathrm{z}=3.73, p<0.001)$.

For testing the effects of exclusion invasive/native ants on herbivore abundance, we combined 62 studies. Egger's regression test for funnel plot asymmetry showed significant asymmetry of these data $(t=2.97$, d.f. $=60, p<0.01$; Supplementary Materials S3, Figure S2). A trim-and-fill method added one additional artificial observation to the original data. With this data, the effects of ant exclusion on hemipteran abundance were significant $(z=0.36$, $p<0.001$ ).

The global effects of ant exclusion on herbivore abundance were significant, and the impacts of ant exclusion was also significant for both native and invasive ant species (Supplementary Materials S4, Table S2; Figure 2b). A comparison between invasive and native ant subgroups using a random effects model revealed no significant difference $(\mathrm{QM}=1.13$, d.f. $=1, p=0.29$, Figure 4a).

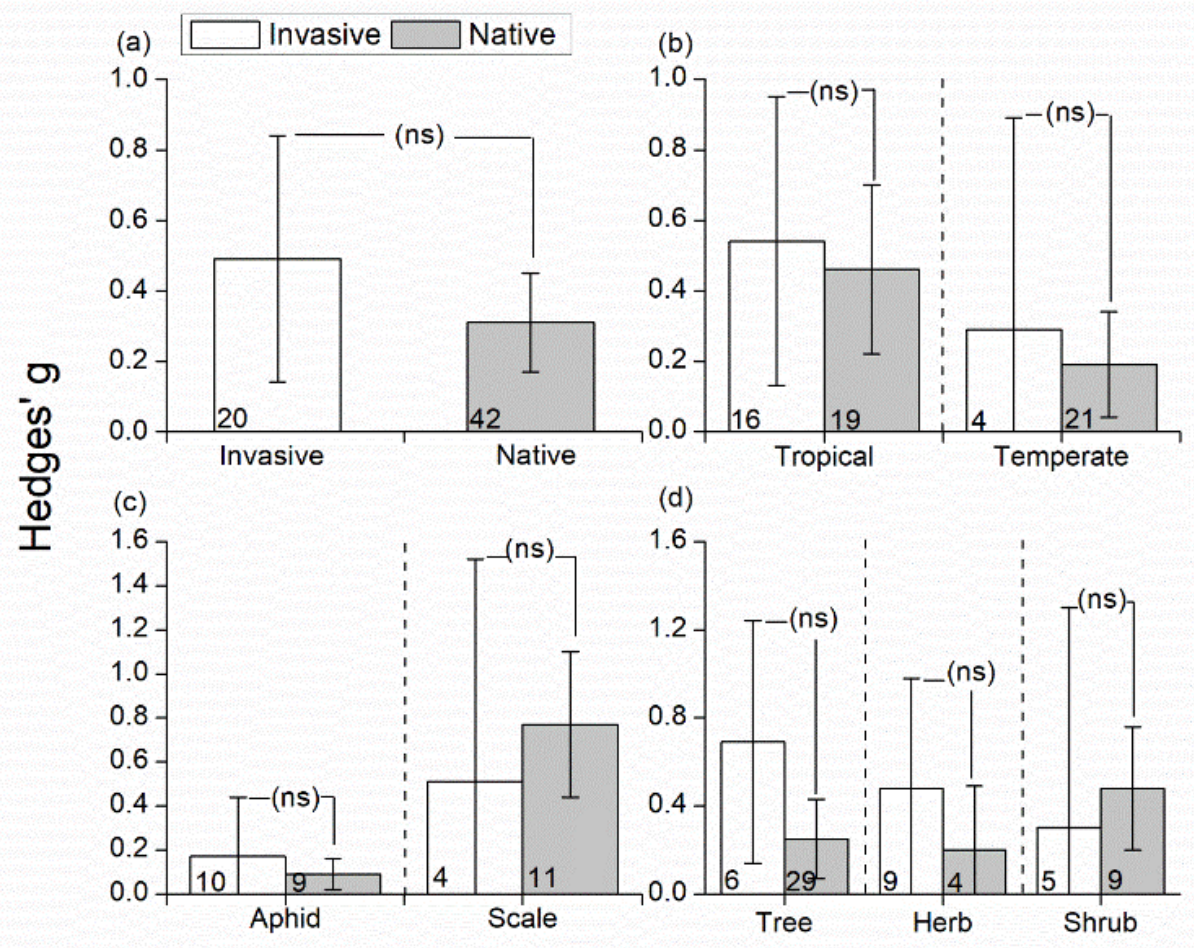

Figure 4. Mean effect size (Hedges' g) and 95\% confidence interval of the effect of exclusion of invasive or native ants on herbivore abundance (a) under different climatic zone (b), Hemiptera type (c), and plant growth form (d). The sample sizes for each category are shown in the box. "ns" not significant. 
We categorized the studies by climatic zone. In the temperate zone, we found no significant difference on herbivore abundance between invasive and native ants $(\mathrm{QM}=0.06$, d.f. $=1, p=0.81$, Figure $4 \mathrm{~b}$ ). The exclusion of invasive ants did not affect herbivore abundance, but the exclusion of native ants had no significant effect on herbivore abundance (Supplementary Materials S4, Table S2). In the tropical zone, there was no significant difference between invasive and native ants $(\mathrm{QM}=0.10$, d.f. $=1, p=0.75$, Figure $4 \mathrm{~b})$, and the exclusion of both native and invasive ants had a significant effect on herbivore abundance (Supplementary Materials S4, Table S2).

We then categorized data by hemipteran superfamily. For ant-aphid interactions, there was no significant difference in herbivore abundance between invasive and native ant exclusion $(\mathrm{QM}=0.30$, d.f. $=1, p=0.58$, Figure $4 \mathrm{c})$. The exclusion of invasive ants did not affect herbivore abundance, but the exclusion of native ants had significant effects on herbivore abundance (Supplementary Materials S4, Table S2). For ant-scale interactions, no significant difference was found between invasive and native ants $(\mathrm{QM}=0.31$, d.f. $=1, p=0.58$, Figure $4 \mathrm{c}$ ); the exclusion of native ants had a significant effect on herbivore abundance, but the exclusion of invasive ants did not (Supplementary Materials S4, Table S2).

Finally, we categorized data by plant growth form. For herbs, the global effects of ant exclusion on herbivore abundance were significant (Supplementary Materials S4, Table S2). However, the exclusion of either invasive or native ants did not affect herbivore abundance (Supplementary Materials S4, Table S2); no significant difference was observed between invasive and native ants in terms of their ability to impact herbivore abundance $(\mathrm{QM}=0.60$, d.f. $=1, p=0.44$, Figure $4 \mathrm{~d})$. For shrubs, the global effects of ant exclusion on herbivore abundance were significant (Supplementary Materials S4, Table S2); the exclusion of invasive ants did not affect herbivore abundance, but the exclusion of native ants had significant effects on herbivore abundance (Supplementary Materials S4, Table S2); no significant difference between invasive and native ants on herbivore abundance was observed $(\mathrm{QM}=0.26$, d.f. $=1, p=0.61$, Figure 4 d). For trees, the global effects of ant exclusion on herbivore abundance were significant (Supplementary Materials S4, Table S2); the exclusion of both invasive and native ants had a significant effect on herbivore abundance (Supplementary Materials S4, Table S2); the between-group difference was not significant $(\mathrm{QM}=2.16$, d.f. $=1, p=0.14$, Figure 4 d).

\subsection{Effects of Invasive/Native Ant Exclusion on Predator/Parasitoids Abundance}

Fifty studies were combined in the meta-analysis of effects of invasive/native ant exclusion on predator abundance (Figure 2c). Globally, ant exclusion showed no significant relationship with predator/parasitoids abundance (SMD $=0.11, \mathrm{z}=1.01, p=0.31$ ). Only two invasive ant species were reported as preying on predators/parasitoids (SMD=-0.39, $\mathrm{z}=-0.86, p=0.39)$. Native ants did not show significant effects on predator/parasitoid abundance $(\mathrm{SMD}=0.13, \mathrm{z}=1.16, p=0.25)$.

\subsection{Effects of Invasive/Native Ant Exclusion on Plant Fitness}

We combined 34 studies on the effects of exclusion of invasive/native ants on plant fitness meta-analysis. Egger's Linear regression test of funnel plot asymmetry (Supplementary Materials S3, Figure S3) showed no significant asymmetry of these data $(\mathrm{t}=-0.33$, $p=0.75)$. There were no significant global effects of ant exclusion on plant fitness (Supplementary Materials S4, Table S3; Figure 2d). Ant exclusion and plant fitness were not significantly related to invasive ants, but the exclusion of native ants was a significant predictor of plant fitness (Supplementary Materials S4, Table S3; Figure 2d). Random effects models revealed no significant difference between invasive and native ants in terms of plant fitness $(\mathrm{QM}=2.13$, d.f. $=1, p=0.14$, Figure 5a). 


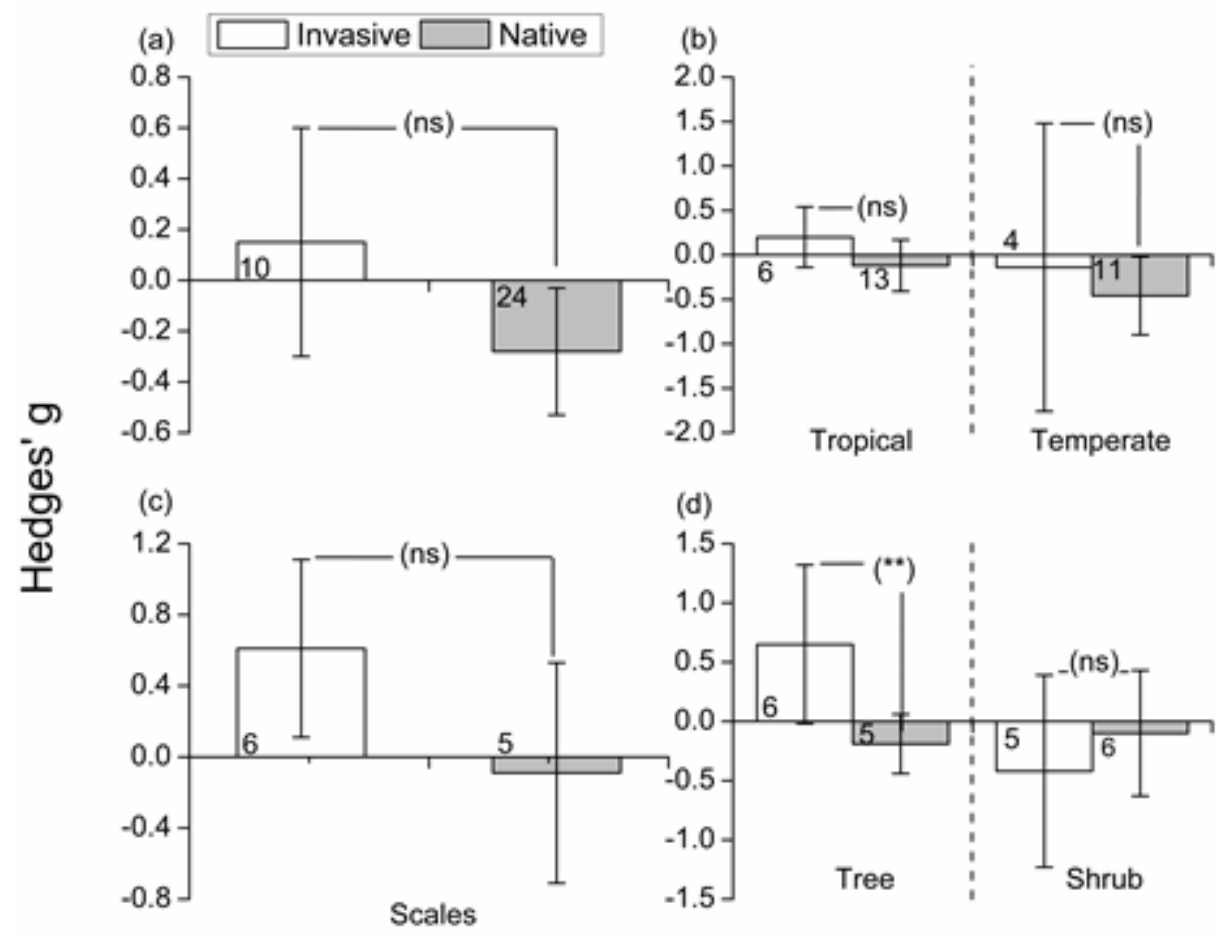

Figure 5. Mean effect size (Hedges' g) and 95\% confidence interval of the effect of exclusion of invasive or native ants on plant fitness (a) under different climate zone (b), Hemiptera type (c), and plant type (d). The sample size for each category is shown in parenthesis. ${ }^{* *} p<0.01$, "ns" not significant.

We categorized the studies by climate zone into temperate and tropical (Figure $5 b$ ). The global effects of ant exclusion on plant fitness in the temperate region were not significant; the exclusion of invasive ants did not affect plant fitness, but the exclusion of native ants had significant impacts on plant fitness (Supplementary Materials S4, Table S3); the between-group (invasive and native ants) comparison revealed no significant difference $(\mathrm{QM}=0.28$, d.f. $=1, p=0.60)$. In the tropical zone, the global effects of native and invasive ant exclusion on plant fitness were not significant (Supplementary Materials S4, Table S3); the between-group (invasive and native ants) comparison also revealed no significant differences $(\mathrm{QM}=1.97$, d.f. $=1, p=0.16)$.

We then categorized data according to hemipteran superfamily (Figure 5c). The global effects of the ant exclusion on plant fitness for the ant-scale insect mutualism were not significant; the exclusion of invasive ants significantly reduced plant fitness, but the exclusion of native ants had no significant effects on plant fitness (Supplementary Materials S4, Table S3); a significant difference between invasive and native ants was found ( $Q M=3.05$, d.f. $=1, p=0.08$ ).

Finally, we categorized data into shrub and tree by plant growth form (Figure 5d). In the shrubs, the global effects of the exclusion of the ant on plant fitness was not significant, and the exclusion of both invasive and native ants did not affect plant fitness (Supplementary Materials S4, Table S3); no significant between-group difference was found $(\mathrm{QM}=0.39$, d.f. $=1, p=0.53)$. In the trees, the global effects of the exclusion of the ant on plant fitness were not significant, and the exclusion of both invasive and native ants had no significant effects on plant fitness (Supplementary Materials S4, Table S3); the between group (invasive/native ant exclusion) difference was significant $(\mathrm{QM}=7.04$, d.f. $=1$, $p<0.01$, Figure 5d).

\section{Discussion}

Our results support the "mutualism intensity" hypothesis, that the exclusion of both native and invasive ants had significant effects on hemipteran abundance, and invasive 
ants had significantly stronger effects on hemipteran abundance than native ants. Both native and invasive ants had significant effects on herbivore abundance, but the effects of invasive ants on herbivores are equal to those of native ants. Additionally, the effects of ants on parasitoids and predators were not significant. Therefore, the current data do not support the "aggressive predator" hypothesis. The "negative trophic cascade" hypothesis was partly supported, as plant fitness (e.g., leaf area, plant height, and seed production) was significantly reduced when native ants were excluded; the exclusion of invasive ants did not influence plant fitness. Taken together, rewiring in the hemipteranant mutualism promotes the invasion of ants, which can be thought of as a new type of "symbiotic invasion" [5]. A high abundance of invasive ant-hemipteran mutualists reduced herbivore abundance, but the detrimental effects of the extraordinarily high density of Hemiptera (themselves herbivores) on host plants may overwhelm the beneficial effects of reduced (non-hemipteran) herbivores, as assumed by Styrsky and Eubanks [26].

\subsection{Effects of Invasive/Native Ant Exclusion on Hemipteran Abundance}

Our data showed that, for each category and each level of category, the exclusion of ants significantly reduced hemipteran abundance (Supplementary Materials S4, Table S2), indicating an intimate relationship between both groups of ants and hemipteran insects. In the tropics, invasive ants had significantly stronger effects on hemipteran when compared to native ants (Figure $3 b$ ). Invasive ants also showed a significantly stronger relationship with Hemiptera than native ants in shrubs (Figure 3d). Invasive ants relied more on Hemiptera in shrubs in tropical areas than native ants. We hypothesized that exotic ant species could easily become invasive in tropical areas, especially as dense forest cover gives way to invasive shrub species and fast-growing secondary forest trees [52].

In five experiments, no hemipterans were observed on the host plant when ants were excluded. On the one hand, it may indicate an intimate co-evolved relationship between these ants and their hemipteran partners [53]. On the other hand, this may be due to other factors influencing interaction occurrence and strength $[54,55]$, for example, the population density of interacting species, host plant status, the time of observations, and weather [56]. Additionally, ant species identity, morphological traits, and level of aggressive behavior may be more important in influencing the strength of their interactions $[32,53]$. Correlations between ant and the hemipteran numbers might be a better index with which to evaluate the ant-hemipteran relationship and assess differences between invasive and native ants [57].

Ants and their hemipteran partners form complex interacting mutualistic networks; ants acquire carbohydrates from hemipteran honeydew, which substantially promotes ant population growth $[58,59]$. Invasive ants tend to form stronger mutualistic relationships with a narrower selection of Hemiptera in comparison to native ants, invasive ants therefore reduce food web diversity and lead to the high abundance of certain hemipterans. As such, the ready supply of carbohydrate excreted from hemipterans may facilitate the invasion of exotic ants.

\subsection{Effects of Invasive/Native Ant Exclusion on Herbivore/Predator Abundance}

The impacts of ants on herbivores varies across different categories, which may in turn vary due to ant predation preference and herbivore traits (e.g., speed of movement, population density, and life history strategies). In three experiments, no herbivores were observed on the host plant. A low density of herbivores will result in weak effects of ant exclusion. Both abundance of ants and herbivores will substantially affect the results of exclusion experiments. Experiments conducted on different types of host plant are also diverse due to the developmental properties (especially developmental rates) of plants. Moreover, ant predation on herbivores may be impeded by physical barriers (such as a specific plant organ) or chemical signals [60], which can all weaken the effects of ant predation on herbivore abundance. 
Although ants are assumed to prey on or harass parasitoids and predators, the abundance of parasitoids and predators was not affected by ants according to our analysis. The effects of ants on parasitoids/predators could be more of a trait-mediated interaction (a change in behavior or preference of parasitoids/predators) rather a density mediated interaction $[61,62]$. Moreover, intra-guild predation may also dampen the results of excluding ants in experiments [63].

The positive effects of ant exclusion on herbivores are most readily observed in specific species of herbivores or in controlled lab conditions with only a few species of herbivores present $[38,64,65]$. In the field, however, herbivores form a community of species on the host plant, and the effects of ants on different species of herbivores are likely variable. For example, less abundant herbivore species or concealed species may benefit from ant predation on competitors or other predators (a form of apparent competition). Fowler and MacGarvin [66] showed that leaf-mining caterpillar richness was higher on trees with Hemiptera-tending ants, while ants were unable to prey on concealed caterpillars, they did protect them from parasitoids. Similar results have been reported in the ant-fig-figwasp system, as pollinating fig wasps entered into the fig fruits to oviposit, and weaver ants preyed on the competitors and parasitoids that oviposit from the outside of the fig fruits [60]. Ants may also dissuade pollinator visitation through aggressive behaviors that are non-consumptive and are not included in the analyses, but they nevertheless reduce floral visitation [67-69].

\subsection{Effects of Invasive/Native Ant Exclusion on Plant Fitness}

Effects of excluding invasive and native ant on host plant fitness were also variable across climatic zones, hemipteran type, and host growth form because the effects of ants are transmitted down the food web. As discussed above, ant predation may either be beneficial or detrimental for plants, depending on their influence on the whole community of insects. Ant protection on herbs may be easily detected and observed when we record leaf damage yet impacts on seed production require more extended periods and involve complex indirect processes (e.g., plant development and defense). Some plants are sensitive to herbivore damage, while others are more tolerant to foraging herbivores. Thus, the defense system of host plants interacting with foraging herbivores is the result of complex physiology and biochemistry processes [70]. The influence of ants can be extraordinarily variable when both herbivorous insects and pollinating insects are present [71]. Ants may protect the plant from herbivore foraging, but ants may also deter pollinators leading to reduced seed production [31].

We did not include ant-plant mutualists in our analyses, because in ant-myrmecophytic interactions ants are attracted by the benefits provided by the myrmecophytic plants, not by hemipteran insects. This exclusion may explain the non-significant effects of ants on herbivory and plants in comparison to Rosumek, et al. [41]. Myrmecophytic plants produce extrafloral nectaries (EFNs), domatia, and food bodies. Almost $80 \%$ of the myrmecophytic plants were colonized by a single ant species, forming an intimate ant-plant interaction [41] Similar results were reported by Zhang, et al. [42], in that the ant-Hemiptera mutualism had significant protective effects on the host plant, but enhanced plant growth or reproductive performance were not observed.

\subsection{Future Considerations}

While ants can protect Hemiptera from natural enemies, ant tending also maintains the stability of host plant-hemipteran interactions by preventing hemipterans from overwhelming host plants [72]. Such beneficial interactions have been reported among native ants, hemipterans, and host plants, which may be a result of diffuse co-evolutionary interactions among them. As for invasive ants, Gaigher, et al. [57] reported that a high abundance of ant-hemipteran mutualists was strongly associated with damage to the host plant, potentially threatening the local ecosystem through their indirect effects. However, the mechanisms behind such a negative correlation were not elucidated. Styrsky and 
Eubanks [26] proposed that the ecological consequences of the interactions among ants, hemipterans, herbivores, and their host plants may be determined by the magnitude of the inter-specific interactions. It is highly likely that effects ripple across multiple trophic levels. Future research should take a multi-trophic approach when evaluating the ecological consequences of invasive ants.

Invasive ants may lead to far-reaching community-level changes within ecosystems through their indirect effects on herbivores, plants, and microbes. On Christmas Island, the invasion of yellow crazy ants promoted local scale insect (Coccoidea) density. A high density of scale insects led to the production of additional honeydew on the leaf surface, which in turn provided the carbohydrates necessary for sooty mold (Ascomycete) growth [73]. Finally, this proliferation of sooty molds led to canopy dieback and even the death of the host tree. Except for direct feeding and damage caused through sooty molds on the leaves, hemipteran insects can also transmit pathogens [74]. The prevalence of sooty molds is positively correlated to the abundance of hemipteran but negatively correlated to plant yield [75], but the diversity and effects of these molds on host plants is poorly studied.

Four important issues should be addressed that relate to ant-hemipteran mutualistic invasion., (1) the type of hemipteran that was favored by invasive ants, (2) the preference of invasive ants with respect to quality and quantity of honeydew production, (3) the host plant preference in the ant-hemipteran mutualism, and (4) the potential effects of the host plant on ant-hemipteran diversity mediated by bottom-up processes. Addressing these issues will give us new insights, allowing us to understand the adaptation of the ant-hemipteran mutualism and perhaps help to control invasive ants. A potential strategy for controlling invasive ants might rely on breaking the interaction between ants and hemipterans by providing additional sugar or sugar baited poison [76-80].

Supplementary Materials: The following are available online at https:/ /www.mdpi.com/article/ 10.3390/agronomy11112323/s1, Supplementary Materials S1 A list of references for data collection. Supplementary Materials S2 Detailed information for each experiment. Supplementary Materials S3 (Figure S1: Funnel plot to show the asymmetry of the hemipteran abundance data. Vertical line shows the random effect estimate of MSD and $95 \%$ confidence interval limits (diagonal dashed line). Figure S2: Funnel plot to show the asymmetry of the herbivore abundance data. Vertical dotted line shows the random effect estimate of MSD and the vertical dashed line shows the fixed estimate of MSD and 95\% confidence interval limits (diagonal dashed line). Figure S3: Funnel plot to show the asymmetry of the plant fitness data. Vertical dotted line shows the random effect estimate of MSD and the vertical dashed line shows the fixed estimate of MSD and $95 \%$ confidence interval limits (diagonal dashed line).) Supplementary Materials S4 (Table S1: Mean effect size (Hedges' g) and $95 \%$ confidence interval of the effect of exclusion of invasive or native ants on Hemiptera abundance under different climatic zone, Hemipteran type, and plant growth form. Table S2: Mean effect size (Hedges' g) and 95\% confidence interval of the effect of exclusion of invasive or native ants on herbivore abundance in different climatic zones, Hemipteran type, and plant growth form. Table S3: Mean effect size (Hedges' g) and 95\% confidence interval of the effect of exclusion invasive or native ants on plant fitness in different climatic zones, Hemipteran type, and plant growth form.).

Author Contributions: Conceptualization, B.W. and M.L.; methodology, B.W.; formal analysis, B.W.; writing-review and editing, B.W., Y.-Q.P., and S.T.S.; funding acquisition, B.W. All authors have read and agreed to the published version of the manuscript.

Funding: This research was supported by the biodiversity investigation, observation, and assessment program (2019-2023) of Ministry of Ecology and Environment of China, the National Natural Science Foundation of China (31570418, 31770463), Yunnan Applied Basic Research Projects (2016FB050).

Institutional Review Board Statement: Not applicable.

Informed Consent Statement: Not applicable.

Data Availability Statement: All the data can be acquired from online supplementary materials of this paper. 
Acknowledgments: We would like to thank Micky Eubanks (department of entomology, Texas A\&M University) for his suggestions and comments on an early version of this manuscript. We also thank three anonymous reviewers for their constructive comments and suggestions that greatly improved the quality of this manuscript.

Conflicts of Interest: The authors declare no conflict of interest.

\section{References}

1. Simberloff, D.; Martin, J.-L.; Genovesi, P.; Maris, V.; Wardle, D.A.; Aronson, J.; Courchamp, F.; Galil, B.; García-Berthou, E.; Pascal, M.; et al. Impacts of biological invasions: What's what and the way forward. Trends Ecol. Evol. 2013, 28, 58-66. [CrossRef] [PubMed]

2. Ehrenfeld, J.G. Ecosystem consequences of biological invasions. Annu. Rev. Ecol. Evol. Syst. 2010, 41, 59-80. [CrossRef]

3. Kennedy, T.A.; Naeem, S.; Howe, K.M.; Knops, J.M.H.; Tilman, D.; Reich, P. Biodiversity as a barrier to ecological invasion. Nature 2002, 417, 636-638. [CrossRef] [PubMed]

4. Traveset, A.; Richardson, D.M. Mutualistic interactions and biological invasions. Annu. Rev. Ecol. Evol. Syst. 2014, 45, 89-113. [CrossRef]

5. Lu, M.; Hulcr, J.; Sun, J. The role of symbiotic microbes in insect invasions. Annu. Rev. Ecol. Evol. Syst. 2016, 47, 487-505. [CrossRef]

6. Tena, A.; Hoddle, C.D.; Hoddle, M.S. Competition between honeydew producers in an ant-hemipteran interaction may enhance biological control of an invasive pest. Bull. Entomol. Res. 2013, 103, 714-723. [CrossRef] [PubMed]

7. Anastasio, O.E.; Mathis, K.A.; Rivera, M.J. Impacts of invasive ant-hemipteran interaction, edge effects and habitat complexities on the spatial distribution of ants in citrus orchards. Agric. Ecosyst. Environ. 2021, 310, 107299. [CrossRef]

8. Milosavljević, I.; Morgan, D.J.W.; Massie, R.E.; Hoddle, M.S. Density dependent mortality, climate, and Argentine ants affect population dynamics of an invasive citrus pest, Diaphorina citri, and its specialist parasitoid, Tamarixia radiata, in Southern California, USA. Biol. Control 2021, 159, 104627. [CrossRef]

9. Richardson, D.M.; Allsopp, N.; D'Antonio, C.M.; Milton, S.J.; Rejmanek, M. Plant invasions-the role of mutualisms. Biol. Rev. 2000, 75, 65-93. [CrossRef] [PubMed]

10. Christian, C.E. Consequences of a biological invasion reveal the importance of mutualism for plant communities. Nature 2001, 413, 635. [CrossRef]

11. Bronstein, J.L. The gift that keeps on giving: Why does biological diversity accumulate around mutualisms. In Plant-Animal Interactions; Del-Claro, K., Torezan-Silingardi, , H.M., Eds.; Springer: Berlin/Heidelberg, Germany, 2021; pp. $283-306$.

12. Holway, D.A.; Lach, L.; Suarez, A.V.; Tsutsui, N.D.; Case, T.J. The causes and consequences of ant invasions. Annu. Rev. Ecol. Evol. Syst. 2002, 33, 181-233. [CrossRef]

13. Ness, J.H.; Bronstein, J.L. The effects of invasive ants on prospective ant mutualists. Biol. Invasions 2004, 6, 445-461. [CrossRef]

14. Del-Claro, K.; Rico-Gray, V.; Torezan-Silingardi, H.M.; Alves-Silva, E.; Fagundes, R.; Lange, D.; Dáttilo, W.; Vilela, A.A.; Aguirre, A.; Rodriguez-Morales, D. Loss and gains in ant-plant interactions mediated by extrafloral nectar: Fidelity, cheats, and lies. Insect Soc. 2016, 63, 207-221. [CrossRef]

15. Hölldobler, B.; Wilson, E.O. The Ants; Harvard University Press: Cambridge, MA, USA, 1990.

16. Miravete, V.; Roura-Pascual, N.; Dunn, R.R.; Gomez, C. How many and which ant species are being accidentally moved around the world? Biol. Lett. 2014, 10, 20140518. [CrossRef] [PubMed]

17. Buckley, R. Interactions involving plants, Homoptera, and ants. Annu. Rev. Ecol. Evol. Syst. 1987, 18, 111-135. [CrossRef]

18. Delabie, J.H.C. Trophobiosis Between Formicidae and Hemiptera (Sternorrhyncha and Auchenorrhyncha): An Overview. Neotrop. Entomol. 2001, 30, 501-516. [CrossRef]

19. Del-Claro, K. Multitrophic relationships, conditional mutualisms, and the study of interaction biodiversity in tropical savannas. Neotrop. Entomol. 2004, 33, 665-672. [CrossRef]

20. Blüthgen, N.; Verhaagh, M.; Goitía, W.; Jaffé, K.; Morawetz, W.; Barthlott, W. How plants shape the ant community in the Amazonian rainforest canopy: The key role of extrafloral nectaries and homopteran honeydew. Oecologia 2000, 125, 229-240. [CrossRef]

21. Blüthgen, N.; Stork, N.E.; Fiedler, K. Bottom-up control and co-occurrence in complex communities: Honeydew and nectar determine a rainforest ant mosaic. Oikos 2004, 106, 344-358. [CrossRef]

22. Del-Claro, K.; Byk, J.; Yugue, G.; Morato, M. Conservative benefits in an ant-hemipteran association in the Brazilian tropical savanna. Sociobiology 2006, 47, 415-422.

23. Moreira, V.S.S.; Del-Claro, K. The outcomes of an ant-treehopper association on Solanum lycocarpum St. Hill: Increased membracid fecundity and reduced damage by chewing herbivores. Neotrop. Entomol. 2005, 34, 881-887. [CrossRef]

24. Messina, F.J. Plant Protection as a Consequence of an Ant-Membracid Mutualism: Interactions on Goldenrod (Solidago sp.). Ecology 1981, 62, 1433-1440. [CrossRef]

25. Horvitz, C.C.; Schemske, D.W. Effects of ants and an ant-tended herbivore on seed production of a neotropical herb. Ecology 1984, 65, 1369-1378. [CrossRef]

26. Styrsky, J.D.; Eubanks, M.D. Ecological consequences of interactions between ants and honeydew-producing insects. Proc. R. Soc. B Biol. Sci. 2007, 274, 151-164. [CrossRef] [PubMed] 
27. Abbott, K.L.; Green, P.T. Collapse of an ant-scale mutualism in a rainforest on Christmas Island. Oikos 2007, 116, 1238-1246. [CrossRef]

28. McPhee, K.; Garnas, J.; Drummond, F.; Groden, E. Homopterans and an invasive red ant, Myrmica rubra (L.), in Maine. Environ. Entomol. 2012, 41, 59-71. [CrossRef] [PubMed]

29. Zhou, A.M.; Liang, G.W.; Zeng, L.; Lu, Y.Y.; Xu, Y.J. Interactions between ghost ants and invasive mealybugs: The case of Tapinoma melanocephalum (Hymenoptera: Formicidae) and Phenacoccus solenopsis (Hemiptera: Pseudococcidae). Fla. Entomol. 2014, 97, 1474-1480. [CrossRef]

30. Ibarra-Isassi, J.; Oliveira, P.S. Indirect effects of mutualism: Ant-treehopper associations deter pollinators and reduce reproduction in a tropical shrub. Oecologia 2018, 186, 691-701. [CrossRef]

31. Villamil, N.; Boege, K.; Stone, G.N. Ant-pollinator conflict results in pollinator deterrence but no nectar trade-offs. Front. Plant Sci. 2018, 9, 1093. [CrossRef] [PubMed]

32. Vilela, A.A.; Del-Claro, K. Effects of different ant species on the attendance of neighbouring hemipteran colonies and the outcomes for the host plant. J. Nat. Hist. 2018, 52, 415-428. [CrossRef]

33. Trager, M.D.; Bhotika, S.; Hostetler, J.A.; Andrade, G.V.; Rodriguez-Cabal, M.A.; McKeon, C.S.; Osenberg, C.W.; Bolker, B.M. Benefits for plants in ant-plant protective mutualisms: A meta-analysis. PLoS ONE 2010, 5, e14308. [CrossRef] [PubMed]

34. Chamberlain, S.A.; Holland, J.N. Quantitative synthesis of context dependency in ant-plant protection mutualisms. Ecology 2009, 90, 2384-2392. [CrossRef]

35. LeBrun, E.G.; Abbott, J.; Gilbert, L.E. Imported crazy ant displaces imported fire ant, reduces and homogenizes grassland ant and arthropod assemblages. Biol. Invasions 2013, 15, 2429-2442. [CrossRef]

36. Hu, G.Y.; Frank, J.H. Effect of the red imported fire ant (Hymenoptera: Formicidae) on dung-inhabiting arthropods in florida. Environ. Entomol. 1996, 25, 1290-1296. [CrossRef]

37. Cole, F.R.; Medeiros, A.C.; Loope, L.L.; Zuehlke, W.W. Effects of the Argentine ant on arthropod fauna of Hawaiian high-elevation shrubland. Ecology 1992, 73, 1313-1322. [CrossRef]

38. Styrsky, J.D.; Eubanks, M.D. A facultative mutualism between aphids and an invasive ant increases plant reproduction. Ecol. Entomol. 2010, 35, 190-199. [CrossRef]

39. Blancafort, X.; Gómez, C. Consequences of the Argentine ant, Linepithema humile (Mayr), invasion on pollination of Euphorbia characias (L.) (Euphorbiaceae). Acta Oecol. Int. J. Ecol. 2005, 28, 49-55. [CrossRef]

40. Schemske, D.W.; Mittelbach, G.G.; Cornell, H.V.; Sobel, J.M.; Roy, K. Is there a latitudinal gradient in the importance of biotic interactions? Annu. Rev. Ecol. Evol. Syst. 2009, 40, 245-269. [CrossRef]

41. Rosumek, F.B.; Silveira, F.A.O.; de Neves, F.S.; de Barbosa, N.P.U.; Diniz, L.; Oki, Y.; Pezzini, F.; Fernandes, G.W.; Cornelissen, T. Ants on plants: A meta-analysis of the role of ants as plant biotic defenses. Oecologia 2009, 160, 537-549. [CrossRef] [PubMed]

42. Zhang, S.; Zhang, Y.; Ma, K. The ecological effects of the ant-hemipteran mutualism: A meta-analysis. Basic Appl. Ecol. 2012, 13, 116-124. [CrossRef]

43. Moher, D.; Liberati, A.; Tetzlaff, J.; Altman, D.G.; The PRISMA Group. Preferred reporting items for systematic reviews and meta-analyses: The prisma statement. PLoS Med. 2009, 6, e1000097. [CrossRef] [PubMed]

44. Abràmoff, M.D.; Magalhães, P.J.; Ram, S.J. Image processing with ImageJ. Biophotonics Int. 2004, 11, 36-42.

45. Borenstein, M.; Hedges, L.V.; Higgins, J.P.T.; Rothstein, H.R. Effect size based on means. In Introduction to Meta-Analysis; John Wiley \& Sons, Ltd.: Cornwall, UK, 2009; pp. 21-32.

46. Grubbs, F.E. Sample criteria for testing outlying observations. Ann. Math. Stat. 1950, 21, 27-58. [CrossRef]

47. R Development Core Team. R: A Language and Environment for Statistical Computing; R Foundation for Statistical Computing: Vienna, Austria, 2021.

48. Vidal, M.C.; Murphy, S.M. Bottom-up vs. top-down effects on terrestrial insect herbivores: A meta-analysis. Ecol. Lett. 2018, 21, 138-150. [CrossRef] [PubMed]

49. Hedges, L.V.; Vevea, J.L. Fixed-and random-effects models in meta-analysis. Psychol. Methods 1998, 3, 486-504. [CrossRef]

50. Schwarzer, G.; Carpenter, J.R.; Rücker, G. Small-study effects in meta-analysis. In Meta-Analysis with R; Gentleman, R., Hornik, K., Parmigiani, G., Eds.; Springer: Cham, Switzerland, 2015; pp. 107-141.

51. Schwarzer, G.; Carpenter, J.R.; Rücker, G. An introduction to meta-analysis in R. In Meta-Analysis with R; Gentleman, R., Hornik, K., Parmigiani, G., Eds.; Springer: Cham, Switzerland, 2015; pp. 3-17.

52. Richardson, D.M.; Rejmánek, M. Trees and shrubs as invasive alien species-a global review. Divers. Distrib. 2011, 17, 788-809. [CrossRef]

53. Del-Claro, K.; Marquis, R.J. Ant species identity has a greater effect than fire on the outcome of an ant protection system in Brazilian Cerrado. Biotropica 2015, 47, 459-467. [CrossRef]

54. Ovadia, O.; Schmitz, O.J. Weather variation and trophic interaction strength: Sorting the signal from the noise. Oecologia 2004, 140, 398-406. [CrossRef]

55. Piovia-Scott, J.; Yang, L.H.; Wright, A.N. Trophic cascades in time: The causes and consequences of temporal variation in the strength of top-down effects. Annu. Rev. Ecol. Evol. Syst. 2017, 48, 281-300. [CrossRef]

56. Baum, J.K.; Worm, B. Cascading top-down effects of changing oceanic predator abundances. J. Anim. Ecol. 2009, 78, 699-714. [CrossRef] [PubMed] 
57. Gaigher, R.; Samways, M.J.; Henwood, J.; Jolliffe, K. Impact of a mutualism between an invasive ant and honeydew-producing insects on a functionally important tree on a tropical island. Biol. Invasions 2011, 13, 1717-1721. [CrossRef]

58. Helms, K.R.; Vinson, S.B. Plant resources and colony growth in an invasive ant: The importance of honeydew-producing hemiptera in carbohydrate transfer across trophic levels. Environ. Entomol. 2008, 37, 487-493. [CrossRef]

59. Zhou, A.; Lu, Y.; Zeng, L.; Xu, Y.; Liang, G. Does mutualism drive the invasion of two alien species? The case of Solenopsis invicta and Phenacoccus solenopsis. PLoS ONE 2012, 7, e41856. [CrossRef] [PubMed]

60. Wang, B.; Lu, M.; Cook, J.M.; Yang, D.-R.; Dunn, D.W.; Wang, R.-W. Chemical camouflage: A key process in shaping an ant-treehopper and fig-fig wasp mutualistic network. Sci. Rep. 2018, 8, 1833. [CrossRef]

61. Frago, E.; Godfray, H.C.J. Avoidance of intraguild predation leads to a long-term positive trait-mediated indirect effect in an insect community. Oecologia 2014, 174, 943-952. [CrossRef]

62. Railsback, S.F.; Harvey, B.C. Trait-mediated trophic interactions: Is foraging theory keeping up? Trends Ecol. Evol. 2013, 28, 119-125. [CrossRef]

63. Finke, D.L.; Denno, R.F. Predator diversity and the functioning of ecosystems: The role of intraguild predation in dampening trophic cascades. Ecol. Lett. 2005, 8, 1299-1306. [CrossRef]

64. Neves, F.D.; Fagundes, M.; Sperber, C.F.; Fernandes, G.W. Tri-trophic level interactions affect host plant development and abundance of insect herbivores. Arthropod-Plant Interact. 2011, 5, 351-357. [CrossRef]

65. Wimp, G.M.; Whitham, T.G. Biodiversity Consequences of Predation and Host Plant Hybridization on an Aphid-Ant Mutualism. Ecology 2001, 82, 440-452. [CrossRef]

66. Fowler, S.; MacGarvin, M. The impact of hairy wood ants, Formica lugubris, on the guild structure of herbivorous insects on birch, Betula pubescens. J. Anim. Ecol. 1985, 54, 847-855. [CrossRef]

67. LeVan, K.E.; Holway, D.A. Ant-aphid interactions increase ant floral visitation and reduce plant reproduction via decreased pollinator visitation. Ecology 2015, 96, 1620-1630. [CrossRef]

68. Ness, J.H. A mutualism's indirect costs: The most aggressive plant bodyguards also deter pollinators. Oikos 2006, 113, 506-514. [CrossRef]

69. LeVan, K.E.; Hung, K.-L.J.; McCann, K.R.; Ludka, J.T.; Holway, D.A. Floral visitation by the Argentine ant reduces pollinator visitation and seed set in the coast barrel cactus, Ferocactus viridescens. Oecologia 2014, 174, 163-171. [CrossRef]

70. De Vries, J.; Evers, J.B.; Poelman, E.H. Dynamic plant-plant-herbivore interactions govern plant growth-defence integration. Trends Plant Sci. 2017, 22, 329-337. [CrossRef] [PubMed]

71. Lucas-Barbosa, D. Integrating studies on plant-pollinator and plant-herbivore interactions. Trends Plant Sci. 2016, 21, 125-133 [CrossRef]

72. Dotseth, E.J.; Larsen, K.J.; Staehle, L.M. Tending ants (Hymenoptera: Formicidae) regulate Dalbulus quinquenotatus (Homoptera: Cicadellidae) population dynamics. Environ. Entomol. 2001, 30, 757-762. [CrossRef]

73. O'Dowd, D.J.; Green, P.T.; Lake, P.S. Invasional 'meltdown' on an oceanic island. Ecol. Lett. 2003, 6, 812-817. [CrossRef]

74. Perilla-Henao, L.M.; Casteel, C.L. Vector-borne bacterial plant pathogens: Interactions with hemipteran insects and plants. Front. Plant Sci. 2016, 7, 1163. [CrossRef] [PubMed]

75. Pitan, O.O.R.; Mwansat, G.; Akinyemi, S.O.S.; Adebayo, O.S.; Akinlosotu, T.A. Effect of mango mealybug and sooty mould attack on mango and the impact of the released Gyranusoidea tebygi Noyes on yield. Fruits 2002, 57, 105-113. [CrossRef]

76. Wäckers, F.L.; Alberola, J.S.; Garcia-Marí, F.; Pekas, A. Attract and distract: Manipulation of a food-mediated protective mutualism enhances natural pest control. Agric. Ecosyst. Environ. 2017, 246, 168-174. [CrossRef]

77. Tay, J.-W.; Hoddle, M.S.; Mulchandani, A.; Choe, D.-H. Development of an alginate hydrogel to deliver aqueous bait for pest ant management. Pest Manag. Sci. 2017, 73, 2028-2038. [CrossRef] [PubMed]

78. McCalla, K.A.; Tay, J.-W.; Mulchandani, A.; Choe, D.-H.; Hoddle, M.S. Biodegradable alginate hydrogel bait delivery system effectively controls high-density populations of Argentine ant in commercial citrus. J. Pest Sci. 2020, 93, 1031-1042. [CrossRef]

79. Tay, J.-W.; Choe, D.-H.; Mulchandani, A.; Rust, M.K. Hydrogels: From controlled release to a new bait delivery for insect pest management. J. Econ. Entomol. 2020, 113, 2061-2068. [CrossRef] [PubMed]

80. Milosavljević, I.; Hoddle, M.S. Laboratory screening of selected synthetic and organic insecticides for efficacy against Argentine ants when incorporated into alginate hydrogel beads, 2021. Arthropod Manag. Tests 2021, 46, tsab072. [CrossRef] 